\title{
Challenges of IT Governance in the Financial Sector: A Study from Saudi Arabia
}

\author{
Wafa Najjar, Shrouq Alharbi, Heba Fasihuddin \\ Department of Information Systems and Technology, College of Computer Science and Engineering, \\ University of Jeddah, Jeddah, Saudi Arabia
}

\begin{abstract}
The financial sector plays a significant role in the economics of all nations. The Saudi Arabian economy ranks amongst the top twenty in the world. Consequently, the financial sector occupies a critical position within Saudi Arabia. Contemporary digital technology has rendered the financial sector heavily dependent upon information technology (IT) as a means of enhancing and extending its operational scope. Hence, efficient governance is required to streamline and utilize information technology. Moreover, the pivotal importance of the financial sector requires that IT governance challenges have to be swiftly identified. However, there is a manifest absence of scholarship regarding IT governance issues not only in the widest sense, but also specifically in the context of the financial sectors. This research seeks to identify the inherent challenges associated with IT governance in Saudi Arabia's financial sector with a view to generalizing any findings and contributing to future research in this field.
\end{abstract}

Keywords - Financial Sector, IT governance, Challenges, Information Technology, Saudi Arabia.

\section{Introduction}

Information technology (IT) governance is widely accepted as an important creative process through which decision-makers can accomplish best value performance [1].

DOI: 10.18421/TEM94-33

https://doi.org/10.18421/TEM94-33

Corresponding author: Heba Fasihuddin,

Department of Information Systems and Technology, College of Computer Science and Engineering, University of Jeddah, Jeddah, Saudi Arabia.

Email: hafasihuddin@uj.edu.sa

Received: 23 July 2020.

Revised: 24 October 2020.

Accepted: 30 October 2020.

Published: 27 November 2020.

(๕) Br-NC-ND (C) 2020 Wafa Najjar, Shrouq Alharbi \& Heba Fasihuddin; published by UIKTEN. This work is licensed under the Creative Commons AttributionNonCommercial-NoDerivs 4.0 License.

The article is published with Open Access at www.temjournal.com
In addition, there is an increased need to align information technology and business goals, thereby emphasizing the importance of IT governance [1].

A recent study reported that organizations which adopt IT governance achieve profit levels which are $20 \%$ higher than those of organizations which do not employ IT governance practices. Unsurprisingly, most organizations are now working towards the implementation of IT governance strategies and standards in order to augment performance levels [2]. Other scholarship has noted that IT governance is the key to business success in general and information technology in particular [3].

Research has generally postulated two principal reasons why IT governance is worthy of serious consideration. The first explanation relates to the complexity and competitiveness which characterize the contemporary business environment, thereby causing it to depend heavily on information technology to sustain efficiency and competitive advantage. The second reason concerns the fact that IT governance enables organizations to make effective decisions related to the application of information technology, in areas such as IT investment, IT principles, and IT infrastructure management. As a consequence of this approach, performance is significantly increased [4]. It has also been observed that effective IT governance contributes to the achievement of corporate governance objectives [5].

It is the contention of the authors that research is limited in the fields of IT governance challenges in general and those which specifically afflict financial sectors. Therefore, the primary purpose of this paper is to explore challenges that may shape the adoption and implementation of IT governance in the Saudi Arabian finance sector. Since Saudi Arabia comprises one of the top 20 most powerful economies in the world [6], any exploration of challenges in the context of the Saudi financial sector may be reflective of challenges in other countries.

This paper is divided into seven sections. Section 2 offers background information pertaining to relevant concepts, such as the concept of IT governance. This section also explores the relationship between IT governance and corporate governance in the context 
of the Saudi Arabian financial sector. Following on from this, Section 3 comprises an overview of pertinent literature on this subject work. Section 4 presents the research methodology employed in this study, the results of which are discussed in Section 5. Finally, the possibility of future research in this field is explored in Section 6 and conclusions are drawn in 7.

\section{Background}

This section provides overviews of the concepts relevant to this study.

\section{IT Governance}

The Information Systems Audit \& Control Association (ISACA) has defined IT governance as "a structure of relationships and processes to direct and control the organization in order to achieve the organization's goals by adding value while balancing risk versus return over IT and its processes" [7]. In addition, ISACA considers IT governance to comprise an essential part of the organization's governance success. It also delivers the necessary structure to allow IT processes, resources, and information to be linked to the organization's strategies and goals [8]. IT governance can also be conceived as the "processes, structures, and relational mechanisms that enable both business and IT people to execute their responsibilities in support of business/IT alignment and the creation of business value from IT-enabled business investments" [9].

IT governance typically employs the best practice approach to the information and technology systems of any given organization that serve its business objectives such as the design, delivery, and scrutiny of IT performance. Thus, it is clear that IT governance is responsible for the internal application of data in a manner which profits an organization and allows it to accrue a competitive edge [8]. In this way, IT governance is critical to the overall employment of information technology [10]. For any IT-based organization, therefore, IT governance remains of critical importance [2].

IT governance encompasses various elements which collectively define IT operation controls, risk management, IT resources, roles, and accountabilities in a way that aligns with the organization's business strategy. Thus, it is essential that good IT governance has to establish proper channels with stakeholders that assure the transparency and alignment with the organization's business goals [11].

\section{The financial sector in Saudi Arabia}

According to the General Authority for Statistics (GASTAT) [12], more than 6000 organizations generated 173 billion Saudi Riyal as revenue in 2018.
The statistics reflect the significance of the financial sector in Saudi Arabia economy [12]. As per Arabia Business industry magazine forecasting, finance sector in Saudi Arabia along with government, and communications sectors will spend around 3.8 billion US dollars, around 14.28 billion Saudi Riyal in 2020. This is about $53 \%$ of total IT spending across all industries in Saudi Arabia [13].

Research by Mushtaque, Ahsan, and Umer has emphasized the extent to which the financial sector has become heavily reliant upon the performance of information technology as a means of improving efficiency, increasing profit, and maintaining reputation [14]. Financial institutions rely on information technology performance and delivery. Consequently, IT governance is essential for the establishment, growth, and sustainability within this sector [14]. Moreover, research indicates that the financial industry is expanding in terms of branches, operations, services, and transactions. Therefore, there is a clear need for more investment in information technology related risk management [14]. Risks in the financial sector involve fraud, money laundering, and terrorist financing. Thus, IT Governance is a necessity which has to be considered in order to achieve the optimal benefits of information technology, not only in finance but also in all other sectors.

\section{Relationship between Corporate Governance and IT Governance}

A review of the relevant literature indicates that the emerging phenomenon of IT governance has been modeled on existing paradigms of corporate governance [4]. Yet whilst corporate governance stresses the need to offer assurances to financiers regarding the returns on their investments, IT governance directs its focus on the augmentation of IT resource performance [1]. Specifically, IT governance comprises a series of structures and procedures designed to safeguard to relationship between IT and the strategies and objectives of any organization. Moreover, IT governance is responsible for determining roles and formulating accountability in a manner which ensures that IT functions in accordance with operational goals.

There is a direct link between IT governance and corporate governance, [15] in that IT governance is an integral aspect of corporate governance. In light of the fact that businesses dependency on IT is currently experiencing a dramatic increase, corporate governance issues cannot be moderated without taking IT issues into consideration. This reinforces the contention that IT governance can be considered an essential element of corporate governance. In fact, since IT has the potential to impact strategic planning and competitive opportunities, it can be conceived as a driver of corporate governance. 


\section{Related Work}

Several studies have attempted to explore the inherent difficulties associated with the adoption of IT governance. Multiple internal and external hindrances have been observed, including resistance to change, knowledge, skills, and level of awareness. Other barriers are based on organizational management factors, such as implementation priorities, lack of executive management support, and resource issues. In addition, IT governance also faces challenges

associated with the flexibility of IT governance frameworks and the need for comprehensive documentation and training. Moreover, other challenges are based on different variables, such as the environment, culture, readiness, capabilities, security, and value drivers [1].

Nicho and Muammar formulated a model designed to address the innate challenges associated with the adoption of IT governance [2]. Known as the ITG Implementation Challenge Model (IICM), it comprises a wide-ranging taxonomic paradigm which needs to be taken into account when seeking to apply any integrated IT governance framework (Figure 1). This is exemplified by the COBIT [7], ITIL [16], and

ISO 27000 [17] series frameworks. The model sets out the challenges involved in implementing IT governance frameworks, either separately or combined.

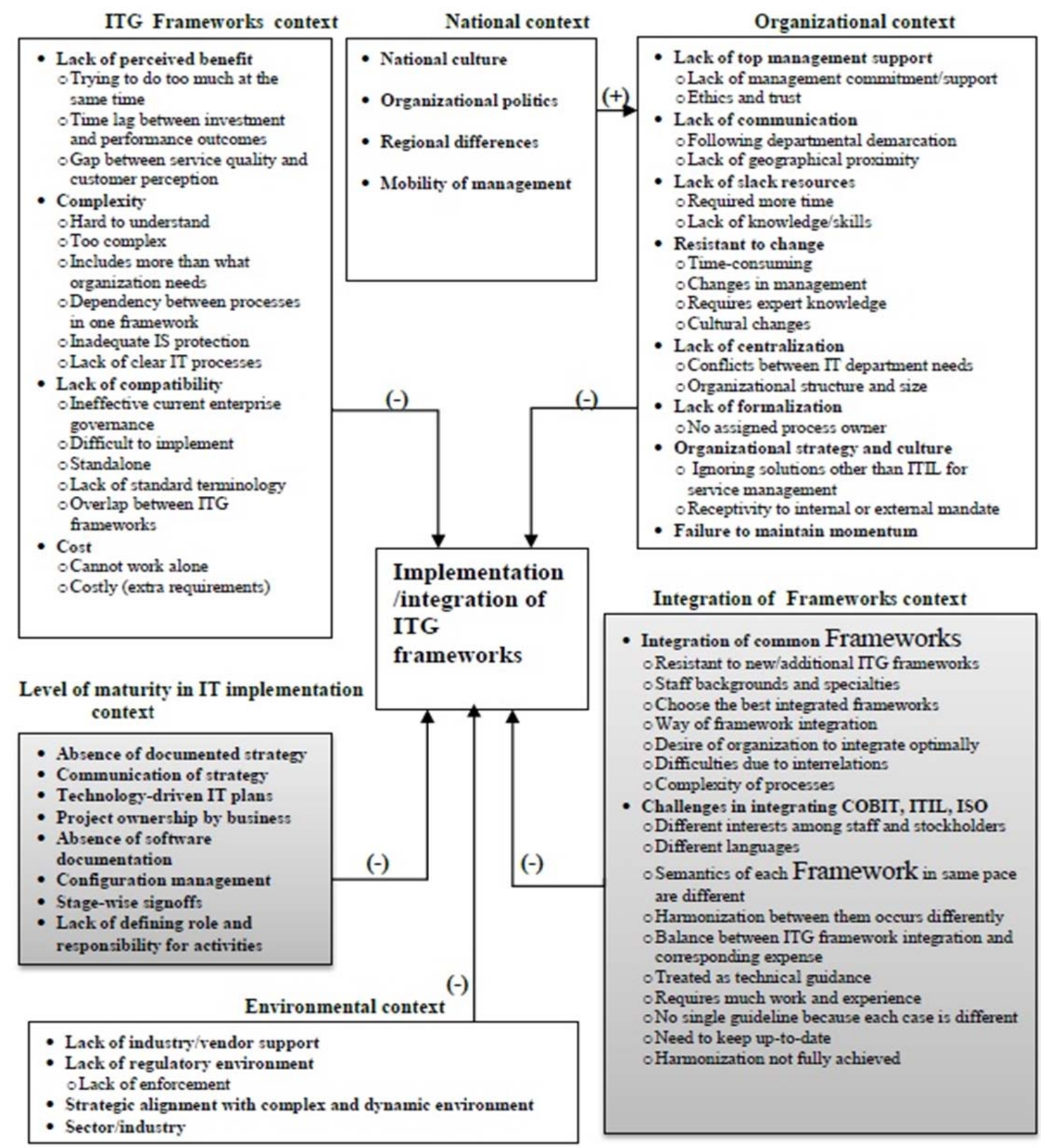

Figure 1. Figure 1 illustrates the ITG Implementation paradigm designed to Nicho and Muammar 
Other research has addressed the challenges in IT governance by identify four principle issues from an IT investment perspective, namely: resistance, the needs for business metrics, the prerequisite for alignment between IT and business, and the necessity for business management tools [3].

De Maere and De Haes adopted a learning perspective and employed the Delphi approach when exploring the difficulties associated with IT governance implementation [18]. This study concluded that learning takes place at multiple points during the process of IT governance implementation. Specifically, these levels comprise the individual level, the group level, and the organizational level.

The individual level refers to the knowledge of IT governance, which is possessed by corporate executives, whereas group level implementation denotes decision making amongst corporate executives. Organizational level implementation refers to the manner in which learning is embedded within IT governance architecture. De Maere and De Haes embraced a framework consisting of four learning processes, which consist of intuiting, interpreting, integrating, and institutionalizing. These processes serve as a link to the individual, group, and organizational levels, as illustrated in Figure 2. The findings of this research reveal that certain inhibitors can delay the implementation of IT governance, the most critical inhibitors being those related to the process interpretation, integration, and institutionalization [18].

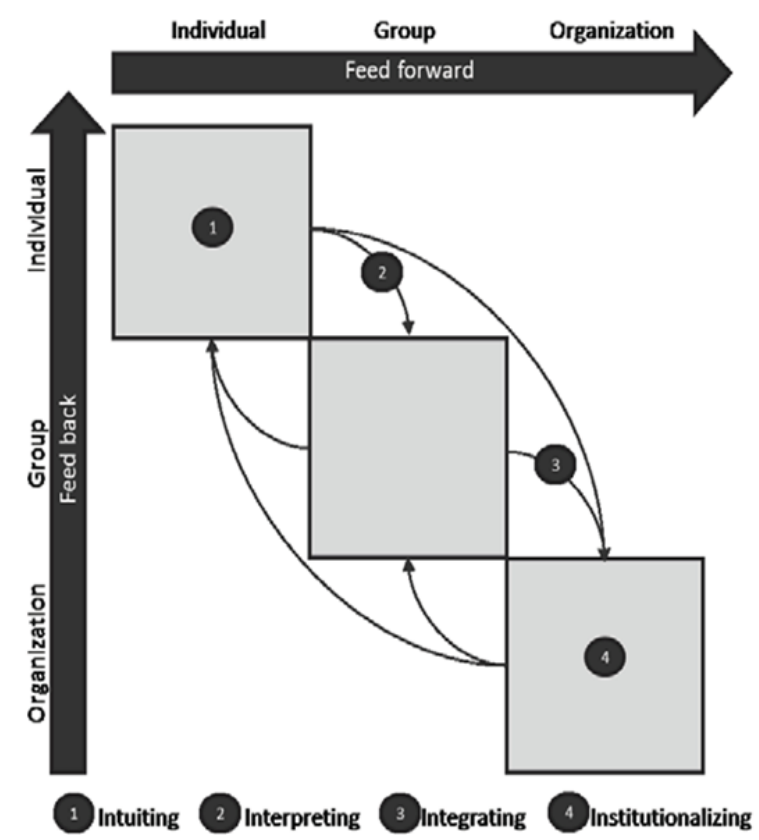

Figure 2. Organizational learning as a holistic process [18]

Another challenge which has been reported in literature concerns governance transparency, or the ability of companies to deliver information to stakeholders in appropriate time and in a way which supports management in the measuring of IT utilization [4]. Whilst this is regarded as a critical issue in corporate governance, it has yet to be adequately noted as an issue specific to IT governance [15].

In a systematic review of the barriers and challenges of IT governance [19], the most important benefits and obstacles facing the implementation of IT governance were addressed. This particular study reviewed an initial 85 articles, which were reduced to 58 articles once duplicate articles had been eliminated. The result of the study identified seven elements correlating to difficulties associated with the implementation of IT governance. These barriers are outlined below.

1. Lack of understanding of the relevant regulations. The rules which control IT governance should be simple, clear, and consistent so that it can be easily understood and applied throughout any organization.

2. Inadequate regulation. There has to exist a healthy balance between mandatory regulations and the freedom to act in a manner which also best serves the organization. Moreover, this has to be supplemented with adequate technical guidance.

3. The lack of persuasive communication. Persuasive input critical. Furthermore, it is the responsibility of higher management strata.

4. Inadequate commitment amongst top management. It is incumbent upon higher management to ensure that the execution of IT governance strategies is communicated and otherwise fostered throughout an organization, thereby ensuring that all relevant parties are committed to the model.

5. Lack of financial and human support. The existence of sufficient human and financial resources is crucial for the successful implementation of IT governance.

6. The lack of perspective of business and IT integration: IT governance should align the needs and requirements of both business and IT.

7. IT staff lack business orientation. IT staff should be given sufficient training in order to ensure that they possess the relevant skills and knowledge to enable them to adequately critical support business functions.

To summarize, the authors believe that the identification of any hindrances to the successful execution of IT governance strategies is critical both in the wider business context and in the specific context of the financial sector. Only once this has been achieved it does become possible to optimize overall performance. The overall comprehensiveness of the aforementioned systematic review of the 
barriers to IT governance renders that particular study amenable to use as a model in the design of the current research. A more detailed presentation of the research design and methodology of the current investigation are outlined in Section 4.

\section{Methodology}

\section{Data Collection Methods}

This research sets out to discover the challenges associated with the implementing of IT governance in Saudi Arabia's financial sector. A quantitative research method was selected wherein an online selfadministered cross-sectional questionnaire was employed. The online questionnaire technique was used to facilitate the inclusion of more participants. Moreover, it has the advantage of allowing research participants to complete the questionnaire at a time and place which is convenient for them.

\section{Sample Selection}

The sample selection strategies employed in this study are known as non-probability sampling and purposive sampling.

Hence, participants were selected in accordance with non-random criteria. Specifically, the selection process required the identifying of potential subjects from within the financial sector in Saudi Arabia. As per the definition offered by the Saudi Arabia Monetary Authority (SAMA) [20], the financial sector includes banking, insurance, financial services, and FinTech. For the purposes of this survey, a group of IT and IT governance experts was selected from amongst the above listed industry types and invited to participate in the survey. Subjects included the heads of IT and IT governance departments.

\section{Survey Design}

Survey construction was based on the findings of the aforementioned systematic review into the barriers and challenges of IT governance [19]. As it was shown in Section 3, this study proposed seven barriers to IT governance. The survey questions in the current research were designed to assess the validity of the seven barriers and their relevance to the financial sector in Saudi Arabia. All participants in the research were apprised of the study's objectives prior to their participation in the survey. It was decided to use the English language as the medium of the questionnaire, the structure of which was designed so that subjects only took approximately four minutes to complete it, as per our findings. In order to ensure that respondents felt at liberty to answer the questions honestly, the survey was conspicuously anonymous.

The survey consisted of seven multiple-choice questions that define the challenges that the Saudi financial sector may face in the implementation of IT governance. For each question, participants were offered multiple potential choices, which comprised: a challenge, somewhat challenging, not a challenge. An open question was added to allow participants to suggest any further challenges they had personally identified concerning the implementation of IT governance. The survey was created using the tools available at www.surveyconsole.com, whereby a link was sent to the selected sample.

\section{Analysis and Results}

This section presents the results of the survey, the principal goal of which was to gather opinions regarding the inherent challenges associated with the execution of IT governance in Saudi Arabia's financial sector. In total, 41 responses were gathered from amongst those supplied by individuals who were selected to participate in the study. The questionnaire presented the respondents with a number of potential barriers to IT governance implementation, which the respondents were required to rank as either a challenge, somewhat challenging, or not challenge. Respondents were also given the chance to volunteer information concerning barrier to IT implementation that they had personally encountered but which were not mentioned in the questionnaire.

The information provided below comprises a descriptive analysis in respect of each challenge included in the questionnaire, followed by a discussion of the other challenges which were identified as a result of the open-ended question.

\section{Lack of understanding of the relevant regulations}

The majority of respondents (71\%) rated lack of understanding of the regulations as a challenge, whereas $24 \%$ regarded it as somewhat challenging, and only $5 \%$ rated it as not a challenge (see Figure 3 ). This result indicates the importance of having precise, simple, and consistent IT governance regulations. In other words, complex and ambiguous IT governance regulations represent a stumbling block for IT governance.

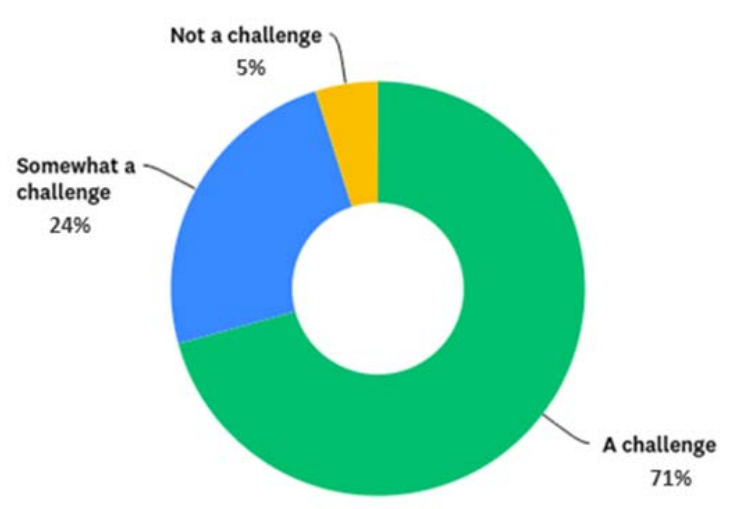

Figure 3. Respondents' perspectives regarding the challenge: Lack of understanding the regulation 


\section{Inadequate Regulations}

More than half of respondents $(56 \%)$ rated the inadequate regulation of IT governance to be somewhat challenging, while less than half (38\%) saw it as a challenge, and only $5 \%$ rated it as not a challenge (see Figure 4). These findings reveal that effective IT governance has to seek a reasonable balance between the necessity for a regulatory structure and the need for flexibility of actions. This equilibrium can potentially be achieved by the creation of technical instructions. However, the fact that such a large number of respondents regarded this area as challenging should raise concern since it is clearly deemed to be a considerable obstacle in IT governance.

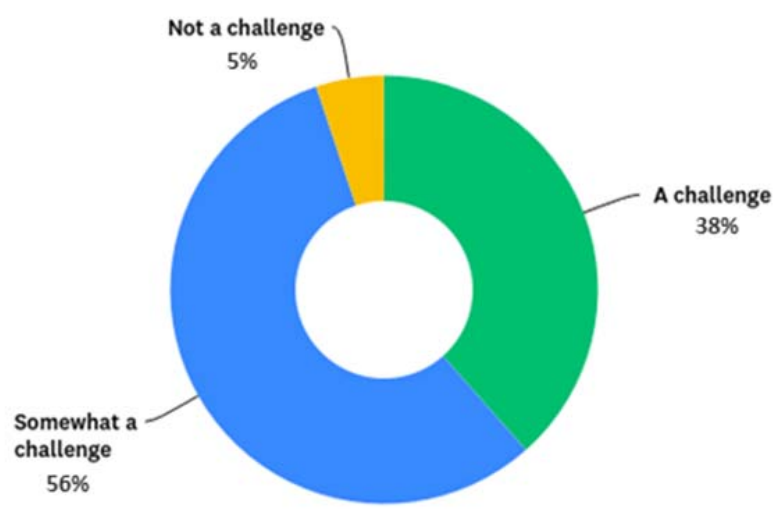

Figure 4. Respondent perspectives regarding the challenge: Inadequate Regulation

\section{The lack of persuasive communication}

The majority of respondents $(68 \%)$ rated the absence of persuasive communication as a challenge, $21 \%$ as somewhat a challenge, and only $11 \%$ rated it as not a challenge (see Figure 5). The results emphasize that if IT Governance is not steered and directed by top management, it is likely to encounter serious impediments to its implementation. Therefore, top management has to assume responsibility for persuasive communication.

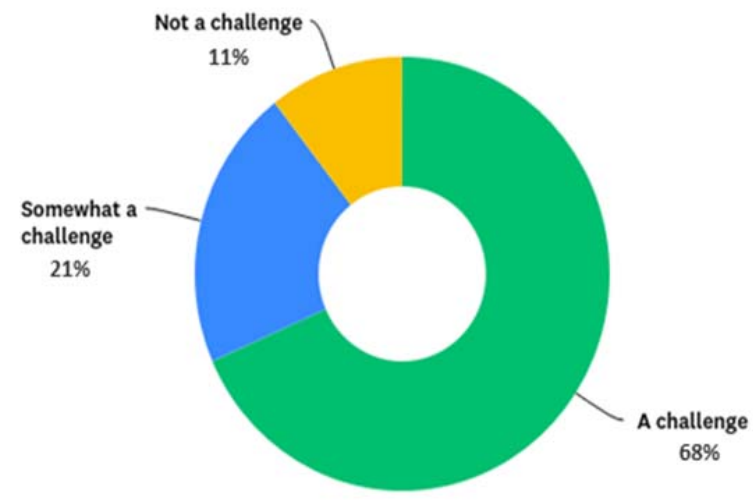

Figure 5. Respondent perspectives regarding the challenge: The lack of persuasive communication

\section{Top Management Less Committed}

Almost half of the respondents (47\%) rated the IT governance adoption by top management as a challenge, $37 \%$ as somewhat a challenge, and $16 \%$ rated it as not a challenge (see Figure 6). The result assures that IT governance is part of corporate governance and considered as a key for the organization success and sustainability. Therefore, the support of top management is required to overcome this challenge.

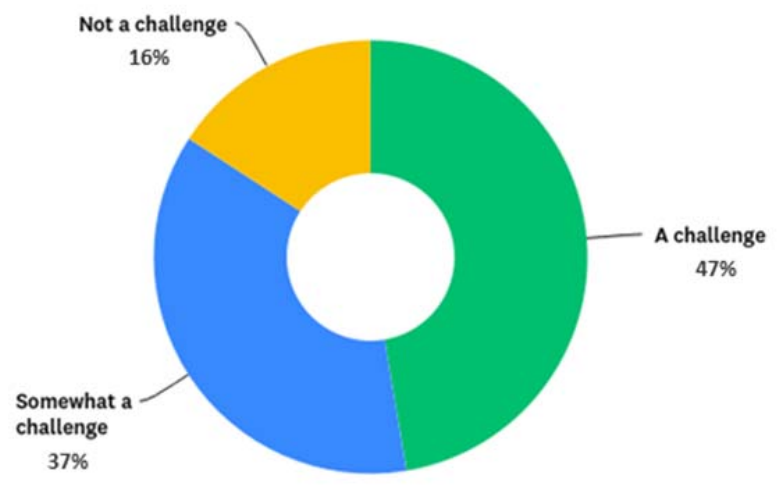

Figure 6. Respondent perspectives regarding the challenge: Top Management Less Committed

\section{Lack of Financial and Human Support}

Half of the respondents $(50 \%)$ rated the lack of financial and human support as a challenge, less than half $(39 \%)$ viewed it as somewhat challenging, and $11 \%$ rated perceived it as not a challenge (see Figure 7). This finding indicates that the provision of an adequate budget and skilled resources are a significant concern for most IT managers and IT governance officers. This underlines the fact that funding and human resource can have a positive impact on the implementation of IT governance.

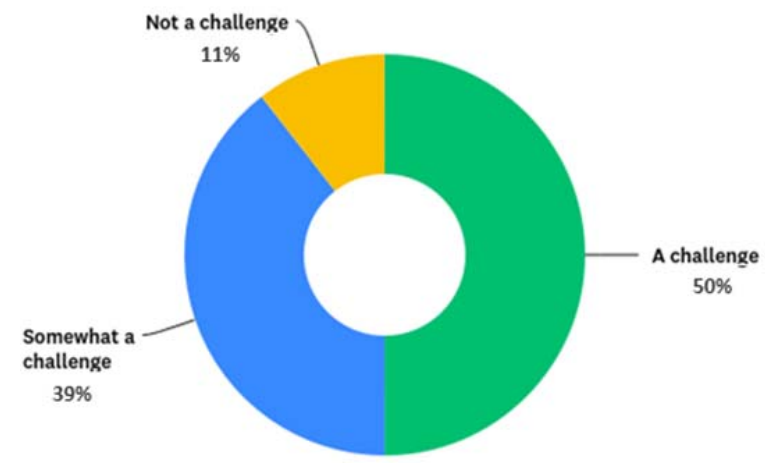

Figure 7. Respondent perspectives regarding the challenge: Lack of financial and human support

\section{The lack of perspective regarding business and} IT integration

While $32 \%$ of respondents rated the lack of perspective of business and IT integration as a 
challenge, almost $60 \%$ of respondents rated it as somewhat a challenge, and only $11 \%$ rated it as not a challenge (see Figure 8). In other words, over half of the respondents considered this challenge to constitute a moderate barrier to IT governance implementation, thereby suggesting that it has the potential to realize a significant impact.

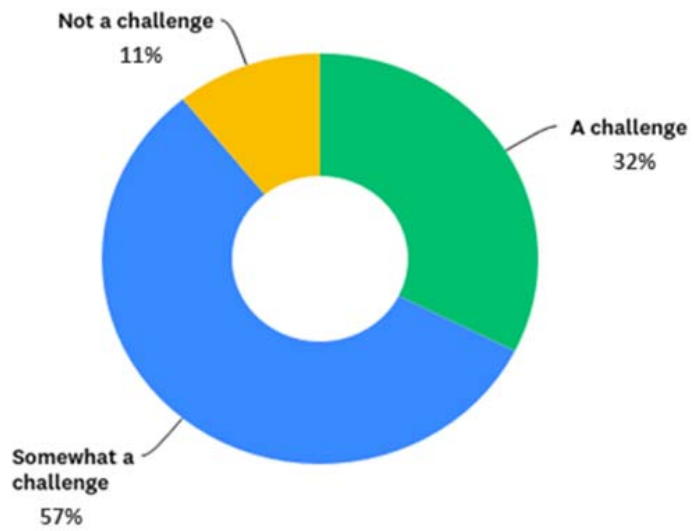

Figure 8. Respondent perspectives regarding the challenge: No perspective of business and IT integration

\section{IT staff lack business orientation}

$40 \%$ of respondents rated the suggestion that IT staffs are less oriented toward the business to comprise a challenge, with $46 \%$ of respondents defining it as somewhat challenging, and the remaining $14 \%$ perceiving it not to be a challenge (see Figure 9). These figures suggest that a clear understanding of business alignment by IT staff is crucial to the successful implementation of IT governance. Although $46 \%$ of the respondents rated this as a moderate challenge, this might be because the participants in this study are all employed in IT related departments and may, therefore, lack extensive business knowledge.

Thus, all seven challenges that were measured in the survey were assessed as a challenge or moderate challenge, since a low percentage of respondents classified them as not a challenge. Therefore, it can be concluded that all seven challenges are critical issues in respect of the successful implementation of IT Governance in the finance sector. As such, they require careful consideration.

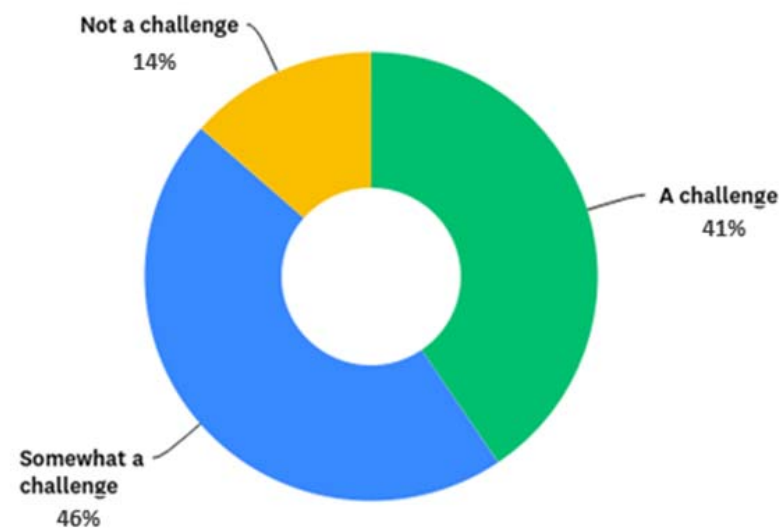

Figure 9. Respondent perspectives regarding the challenge: IT staff lack business orientation

\section{Open Question}

The majority of respondents were able to suggest additional challenges. However, many of these were closely linked to the seven identified challenges already included in the multiple-choice questions. These suggestions include:

- Awareness and knowledge of IT governance

- IT governance workshops

- IT governance inclusion in organization strategy

- IT staff and understanding of business needs

Conversely, a number of respondents highlighted barriers which could usefully be incorporated into future research. These include the following:

- Lack of governance solution technology

- Clear segregation of duties

\section{Future Research}

There is an obvious dearth of research into the identification of barriers to IT governance implementation within the Saudi Arabian financial sector. Thus, future studies might adopt different perspectives, for example by examining and analyzing each challenge in order to identify ways of overcoming these challenges. In addition, there is a clear need to conduct research which employs a more in-depth focus in respect of diverse variables in the financial sector in order to locate and address any barriers. Potential areas for exploration include banking, insurance enterprises, financial services, and FinTech. 


\section{Conclusion}

Information Technology (IT) governance is an emergent practice which offers support to decisionmakers. Indeed, it has become increasingly for organizations to adopt IT governance in order to optimize their performance. IT governance has evolved to support organizations in the integration of IT infrastructures and the delivery of high-quality services. Furthermore, the financial sector relies heavily on information technology to improve and expand its services and operations. As a result, there has emerged a clear need for capable IT governance in order to streamline and utilize information technology efficiency.

The principal objective of this paper has been to openly explore contemporary barriers and opportunities in respect of IT governance in the Saudi Arabian financial sector, not least in terms of its potential to bolster the economy in the KSA. Specifically, this study has utilized the challenges identified in a review of the relevant literature in order to create a questionnaire, the purpose of which was to gain insights from IT and governance professionals. The 41 responses to the questionnaire were used to identify the extent to which the specified variable represented challenges or barriers to IT governance implementation. It is anticipated that the results of this study will be of value in the shaping future research initiatives.

\section{References}

[1]. Al-Farsi, K., \& Haddadeh, R. E. (2015). Framing information technology governance in the public sector: Opportunities and challenges. International Journal of Electronic Government Research (IJEGR), 11(4), 89-101.

[2]. Nicho, M., \& Muamaar, S. (2016). Towards a taxonomy of challenges in an integrated IT governance framework implementation. Journal of International Technology and Information Management, 25(2), 2.

[3]. Wilkin, C. L., \& Riddett, J. (2009). IT governance challenges in a large not-for-profit healthcare organization: The role of intranets. Electronic Commerce Research, 9(4), 351-374.

[4]. Joshi, A., Bollen, L., \& Hassink, H. (2013). An empirical assessment of IT governance transparency: Evidence from commercial banking. Information Systems Management, 30(2), 116-136.

[5]. Panetta, I. C., Leo, S., Santoboni, F., \& Vento, G. (2017). It Governance in the Banking Sector: Evidence from Italy, Germany, France and Spain. Economic Review: Journal of Economics and Business, 15(2), 63-76.

[6]. G20. (2020). G20 Participants. Retrieved from: https://g20.org/en/about/Pages/Participants.aspx [accessed: 10 March 2020].
[7]. Information Systems Audit Control Association. (2018). COBIT 2019 Framework: Introduction and Methodology: ISACA.

[8]. Abu-Musa, A. A. (2007). Exploring information technology governance (ITG) in developing countries: an empirical study. The International Journal of Digital Accounting Research, 7(13), 71-117.

[9]. Löfstedt, T. (2015). Exploring Integrated Management Systems-Challenges and Potentials in Relation to IT Governance. In IRIS38-System design for, with and by users, Oulu, Finland, August 9-12, 2015 (pp. 1-13).

[10]. Debreceny, R. S. (2013). Research on IT governance, risk, and value: Challenges and opportunities. Journal of Information Systems, 27(1), 129-135.

[11].de Souza Bermejo, P. H., Tonelli, A. O., de Brito, M. J., \& Todesco, J. L. (2012). Implementation of information technology (IT) governance through IT strategic planning. African Journal of Business Management, 6(45), 11179-11189.

[12]. General Authority for Statistics. (2018). Money and Insurance Survey. Retrieved from: https://www.stats.gov.sa/sites/default/files/nshr_msh lml_wltmyn_2018_0.pdf [accessed: 12 May 2020].

[13]. Bridge, S. (2020). Total IT spending in Saudi Arabia forecast to hit $\$ 37 \mathrm{bn}$ in 2020. Arabian Business. Retrieved from:

https://www.arabianbusiness.com/technology/440558total-it-spending-in-saudi-arabia-forecast-to-hit-37bnin-2020 [accessed: 12 May 2020].

[14]. Mushtaque, K., Ahsan, K., \& Umer, A. (2015). IT Governance Issues in Banking Sector of Pakistan. Res. J. Recent Sci. 4(3), 9-15.

[15]. De Haes, S., Huygh, T., \& Joshi, A. (2017). Exploring the contemporary state of information technology governance transparency in Belgian firms. Information Systems Management, 34(1), 2037.

[16]. AXELOS. (2019). ITIL Foundation, ITIL 4 edition: TSO.

[17]. International Organization for Standardization, (2018). ISO/IEC 27000- Information technology Security techniques -Information security management systems -Overview and vocabulary (5th ed.). Switzerland: ANSI.

[18]. De Maere, K., \& De Haes, S. (2017, December). An Investigation of the Theory-Practice Gap in the Context of IT Governance. In European Conference on Management, Leadership \& Governance (pp. 530537). Academic Conferences International Limited.

[19]. Yudatama, U., Nazief, B. A. A., \& Hidayanto, A. N. (2018, February). Benefits and barriers as a critical success factor in the implementation of IT governance: Literature review. In 2017 International Conference on ICT for Smart Society, ICISS 2017 (pp. 1-6). Institute of Electrical and Electronics Engineers Inc..

[20]. Saudi Arabian Monetary Authority, (2020). SAMA Functions. Retrieved from:

http://www.sama.gov.sa/enUS/About/Pages/SAMAFunction.aspx [accessed: 15 June 2020]. 